\title{
Online Programming Language Learning Using Massive Open Online Courses in Saudi Universities
}

\author{
Ahmad Alaqsam ${ }^{1}$, Fahad M Ghabban ${ }^{2}$ \\ ${ }^{1}$ Department of Information System, Faculty of Computing, The university of Tabuk, \\ ${ }^{2}$ Information System Department, Faculty of Computing, Taibah University \\ Fghaban@taibahu.edu.sa
}

\begin{abstract}
Several studies stated that Computer Science (CS) students at Saudi Arabia universities face difficulties in programming languages learning (PLL) and need more assistance. Fortunately, Massive Open Online Courses (MOOCs) have been recognized as modern means that could be acceptable amongst CS learners. This piece of research aims to clarify the importance of enhancing PLL via MOOCs in Saudi Arabia. This research applied a quantitative research approach that utilized questionnaire as a research instrument. The survey was distributed among CS students to illustrate the current situation of the students' need and acceptance of MOOCs on PLL. The investigation included 132 participants from different departments in the faulty of Computer Science (CS) at Umm Alqura University and Taif University in Saudi Arabia. The questionnaire results show that $98 \%$ believe that they need additional courses in PLL and $94 \%$ are accepting the idea of utilizing MOOCs on PLL, on the other hand, the results also show that $77 \%$ of the participants have not attended a single PLL course via MOOC. Other results and future research are discussed as well.
\end{abstract}

Key words: Programming language learning; education of sustainable development; massive open online courses (MOOCs); information and communication technologies (ICT)

\section{INTRODUCTION}

Learning how to programme is an essential skill in Computer Science (CS) education [1,2]. However, a number of studies have stated that CS students face difficulties in programming languages learning (PLL) [2-4]. Lu et al.[1] mention that practicing programming languages requires more efforts from students and teachers. Many previous investigation agreed that learning programming language is not an easy task for large number of students [1-3]. They point out that students suffer to achieve programming languages courses especially those who are at the first stage. In Saudi Arabia, Garcia[5] highlights that the situation of PLL courses at King Saud University need to be enhanced and heightened. Moreover, at Tabuk University Alakeel[6] reported that the performance of many student in programming language is strikingly weak and unacceptable. Furthermore, he points out that the situation is almost similar in most universities around the country. Also, Alshaye, Jumaat, and Tasir[7] emphasize that students face difficulties in programming practical sessions in Saudi Arabia. Ullah et al.[8] emphasize that the difficulties of programming languages have been concerning student. Also, they point out that the rate of failures is high at universities. Moussaet al.[9] conducted an experimental study at King Abdul-Aziz University in computer science department and indicate that students struggle with programming courses and need technological assistance. Indeed, students at universities still need more effort to increase their ability to comprehend programming [10].

Although there are several choices to enhance PLL, MOOC recognized as an effective mean[11-13]. Therefore, this study investigates MOOCs' effectiveness in PLL in Saudi Arabia where the situation is more ambiguous and need further investigation $[14,15]$. The paper contains the following sections. After the introduction the second section provides related literature that shows the previous efforts on improving online PLL technologies. After that, in third section the researchers clarify the theoretical background. The fourth section explains the research method, approach and data collection procedure. The results of the survey are illustrated in the fifth section and the discussion with conclusion in the sixth one. 
Ahmad Alaqsam et al., International Journal of Emerging Trends in Engineering Research, 9(2), February 2021, 116 - 131

\section{RELATED RESEARCH}

\subsection{Online Programming Language Learning}

Ristic, Milosevic, and Urosevic[16] highlight that programming language is an essential subject that should be offered at universities, college and also schools. It is understood that Computer Science subjects are significant and programming languages are one of the most notew orthy subject that should be learned professionally [1,17]. Nevertheless, a number of studies state that CS students face difficulties in programming languages learning (PLL) [1-3].

However, researchers realized that integrating online resources and educational technology tools in programming languages learning procedure is one of the most beneficial means. Consequently, there have been a number of studies on online programming languages learning. For example, Shaw[18] experience the benefits of online forum in programming learning and found that it is useful to improve student performance, influencing student positively and significantly improving the student satisfaction. Saito, Sasaki, and Washizaki[19] provide a programming learning website combined with Scratch that is named (WeLas) to enhance programming skills in Java programming language and found that the prototype was appropriate and beneficial for students. Lee and Ko [20] applied a pretest-posttest investigation via using Codecademy and Gidget and suggest that using online tools in teaching and learning programming is successful and effective [20]. H. Wu, Liu, Qiu, and Liu[21] tested the efficiency of an online judge system in programming learning and found that the system increases the interest of student and the student ability to solve exercises. Also, learnability and think ability of student were developed. Saito et al.[19] test the effectiveness of six different tools in programming learning comprehension test and found that all tolls enhanced the test. The tools were Scratch, Viscuit, CodeMonkey, Lightbot, OSMO Coding and Robot Turtles[19]. Su and Hsu[22] designed a Web-based Visualized OOP Learning Tool (VLT-OOP) to make OOP learning easier. Ali and Smith[23] used Alice to facilitate programming learning for novice students. A number of studies utilized Moodle which is an online learning platform to test the performance of student in learning programming [24,25]. Cabadaet al.[26] provided an online environment for Java language learning which was an enjoyable tool for learners. Also, the study shows that the performance of students used the tool was better than the performance of other who did not use it. Yan et al.[27] offered a website called PROVIT to improve $\mathrm{C}$ language learning process for teachers and students and found that it was beneficial tool in teaching procedure.

It is emphasized that online programming learning tools enhance teaching and learning programming dramatically [28]. For example, the rate of failures decreased with very good student achievement, make programming courses more acceptable amongst student and improve student thinking and skills. Furthermore, teachers could save time and efforts. Cai[29] recommends online platform for teaching computer science courses after a very successful attempt that was conducted at Colorado Technical University. Keunget al.[30] emphasize the effectiveness of online interactive application for learning object-oriented programming after conducting their successful investigation. Lu et al.[1] clarify the beneficial of online assessment tool for programming learners. Song et al.[31] indicate that online free courses play a significant role in programming language education especially those that provide feedback, assessment and interaction. Rosatoet al.[32] highlight that a well design online professional development tool is an effective mean to teach CS courses. Moraet al.[33] clarify that free online courses are facilitating education to meet society needs especially in computer science subjects. Indi[34] stated that online platform is a unique tool for teaching Java programming language where student improve their problem solving ability and programming ability. Hwang, Liang, and Wang[35] claim that online learning tools develop students' acquaintance and skills in programming languages courses. Teusner, Hille, and Hagedorn[36] highlight that online courses are a proper way to have practical practices in programming languages. Cabrera, Villalon, and Chavez[37] verify that online learning improve programming learning noticeably. Malliarakis, Satratzemi, and Xinogalos[38] stated that learning programming through online games shows an encouraging result that motivate researchers to pay more attention. Edwards and Murali[39] found that online short practices applications in programming language learning are acceptable and beneficial.

As it is realized through the literature, the beneficial and effectiveness of using online tools in programming languages learning is notable in several investigations. However, it would be helpful for PLL procedure to realize the current online PLL tools that are applied nowadays. For this purpose, the researchers reviewed 160 publications in online programming languages learning technologies between 2013-2018, and it is found that there are four kinds of online tools that are applied in PLL which are: online websites, online courses, online software and general online learning materials. 
Ahmad Alaqsam et al., International Journal of Emerging Trends in Engineering Research, 9(2), February 2021, 116 - 131

Interestingly, it is clarified that online courses are the current trends of the online PLL tools. Furthermore, the researchers found that MOOCs' studies are the most applied online PLL courses.

\subsection{MOOC is an Effective Educational mean for PLL}

Several recent researches recommended the utilization of MOOCs in PLL. Sarkar et al.[11] investigated the use of programming MOOCs for one year and highlight their beneficial especially MOOC on Java learning. Shin et al.[12] state that programming learning via MOOCs has been a huge trend in self-learning. They provide a tool that enhance current programming learning online courses. Malchow et al.[13] improve a remote lab for learning hardware programming via MOOCs and the report a good reaction and participation by learners. Yulianto et al. [40] emphasize that PLL is difficult subjects for many learners and MOOCs facilitate PLL and enhance learning and teaching outcome. Psathas[41] after conducting an investigation on the students' utilization of MOOCs on python learning, they found that programming learning via MOOCs enhance learners' experiences and develop their career. Herrera-urgiles and Peralta-bravo[42] support MOOCs with gamification elements to improve the students' performance in Object-Oriented programming courses. Oktavia [43] found significant results in examining the effectiveness of edX and Coursera MOOCs in programming learning and suggest researchers to conduct more studies specially in higher education sector. Lepp et al.[44] found that MOOCs are effective way in programming learning and they introduced a troubleshooters for programming practices that are provided via MOOCs and realized that $90 \%$ of the participants believe that troubleshooters are helpful and $80 \%$ were happy to utilize them. Luik [45] confirmed that MOOCs are beneficial and effective on PLL.

Indeed, MOOCs have gained admiration from educational institutions and learners [46-48]. This kind of information communication technology provide huge open learning environment where instructors and students have the opportunity to communicate easily with no fairs. Unlike the traditional learning procedure, MOOCs provide knowledge to students who are different in their educations, ages, incentives, goals and experiences. Some researchers believe that MOOCs could be an essential part of the traditional learning procedure $[48,49]$.

Interestingly, it was stated that more than 6800 courses offered by different universities via MOOCs in 2016 [50]. Courses had been increasing dramatically from less than 2000 courses in 2012 to more than 11000 courses in 2018 [51]. Numerous researches report that a large number of students around the world prefer using MOOCs as online learning resources [52,53,62-65,54-61]. Interestingly, Shah [50] stated that the total number of students registered in some courses could reach millions. According to the most recent study by shah [51], between 2012-2018 the total number of learners registered in MOOCs reached 101 million and In just 201820 million students signed up for one course or more. The top five MOOC registered users are Coursera with 37 million, edX with 18 million, XuetangX with 14 million, Udacity with 14 million and FutureLearn with 8.7 million [51]. Also, more than 900 universities around the world had started $11.4 \mathrm{~K}$ courses [51]. Interestingly, MOOCs have been considered by prestigious and top universities[51]. In addition, the number of online degree announced by MOOC providers increased from 15 in 2017 to 47 in 2018 [51].

The heterogeneity, massiveness and openness are main characteristics that make MOOC a unique kind of online learning platform $[48,66]$. One course on MOOC could include thousands of learners who have different culture, experience and inspiration. MOOCs are open for anyone who are anywhere and at any time with no fairs, obligations, conditions and harms on the planet [48].

\subsection{PLL via MOOCs at Saudi Universities}

Indeed, MOOCs have not been well introduced in Saudi Arabia yet. As it will be discussed later the survey results show that $98 \%$ of the CS students need more help in PLL. Also, 95\% of them eager to utilize MOOCs to improve PLL procedure. But, yet $77 \%$ of them have not attended a single PLL course via MOOCs. Indeed, the intention of developing MOOCs at educational institution in Saudi Arabia still weak and the number of Arabic MOOCs are few [67]. According to Shah [51], the universities participated in MOOCs from everywhere in the world in 2018 were more than 940 universities and just 5 of them were from Saudi Arabia. The number of courses provided via MOOCs in 2018 were 11400 courses where Saudi Universities participated in 11 courses and just one of them belonged to CS field which was introduction to JAVA programming language [51]. Several studies emphasize that there is a lack of investigations examined the influences that affect the learners' acceptance of MOOCs in Saudi Arabia [14,15]. The advancement and development of open educational resources (OER) in Arab countries and Saudi Arabia is still in its early stages $[48,68]$. 
Ahmad Alaqsam et al., International Journal of Emerging Trends in Engineering Research, 9(2), February 2021, 116 - 131

However, the interest of providing MOOCs in the Saudi education have been discussed and investigated by some researchers from Computer Science and Educational sectors. For instance, Almuhanna (2018) conducted a PhD research to investigate the implications of MOOCs on the students' Saudi culture. The researcher focuses on the impact of MOOCs' design on the students live and social environment. The researcher found positive influences of using MOOCs on students. However, the research did not suggest a model or a guide line for enhancing the students' utilization of MOOCs. The researcher emphasis that MOOCs are preferable educational technologies among Saudi students but need further investigations to clarify the students' acceptance of MOOCs especially MOOCs provided in foreign languages Almuhanna (2018).

Another attempt has been done by Almutairi (2018)who examined the influences of applying MOOCs on blended learning among Saudi women's in higher education sectors and identified the pattern of women's engagements in blended learning. The researcher developed a model based on a combination of three designed survey which are the National Survey of Student Engagement (NSSE), the UK Engagement Survey (UKES), and the Student Engagement Questionnaire (SEQ). The researcher found that integrating MOOC with the traditional way of learning enhanced the nature of learning and created new ways of learning such as collaborative learning, reflective learning and integrative learning Almutairi (2018). However, the research did not pay attention to the influences that affect the behaviour of students to engage in utilizing blended learning via MOOCs.

Also, Alshehri (2018) Studied the impact of learners' motivation and gender on MOOCs completion in Saudi Arabia. The researcher applied Keller's ARCS motivation model which represents attention, relevance, confidence, and satisfaction. The researcher found strong relation between gender and motivation where women were more motivated to utilized MOOC. Also the relation was significant between motivation and MOOCs completion Alshehri (2018). However, the research needed to be supported with Information Systems theories that discuss how the motivation would influence the behaviour of students to accept technology.

\section{THEORETICAL BACKGROUND}

\subsection{Learning and Motivation in the MOOCs}

Motivation drives individuals to self-realization [71]. It is a group of influences that affect the personal adoptions and actions. A number of researches highlight that investigating the behaviour of students towards the use of MOOCs will explains the students' motivation, engagement [72,73] and satisfaction[14,74]. It is emphasized that knowing the factors that influence the motivation of learners towards their use of technology is an essential part of the development. In fact the motivation of students in utilizing ICTs affect their behaviour to accept them $[48,58]$. Also, the behaviour of students and the contents of courses are main influences affecting learner's motivation and engagement in MOOCs $[48,75]$. Therefore, MOOC designers should be aware of influences that affect students' behaviour and motivations.

\subsection{The students' use of MOOCs on PLL.}

Unfortunately, there are handful studies that have been done in investigating the students' behaviour towards the use of MOOCs on PLL.For example, Yulianto et al.. (2016) provide a model that guides educational institutions to design and use programming MOOCs along with traditional PLL. They utilised cognitive theory, constructive theory, and social situated learning theory and suggest (user, data layers, and system) to be the application layers.

Also, Economides and Perifanou (2018) developed a model to characterize MOOCs. The aim of the research is to provide a scale for determining motivational influences encouraged learners to enrol in programming MOOCs and then test its effectiveness. They named it MOOC Affordance Model(MOOC-AM). It contains eight dimensions which are 1) Massiveness, 2) Openness, 3) Interaction4) 5) Autonomy 6) Assistance 7) Ubiquity and 8) Assessment. The model was developed based on Self Determination Theory (SDT) and applied on Python course provided via MOOC. The researcher found that the model guides to appropriate design of MOOCs [76]. 
Ahmad Alaqsam et al., International Journal of Emerging Trends in Engineering Research, 9(2), February 2021, 116 - 131

A third example is Luik et al.. (2019) who proposed an instrument to measure students' motivation on utilizing MOOCs on PLL. They applied Value-Expectancy Theory and come out with seven main factors which are expectancies on course, personal suitability, suitability for family and work, perceived ability, certification, usefulness and social influence. The scale is called Factors Influencing Enrolment in MOOC (FIEM). They recommend the scale to be utilized by future investigations conducted on MOOCs.

\subsection{MOOCs' Advantages and Limitations}

Here are some of the MOOCs' advantages brought from the literature:

- It is realized as a well support for education of sustainability development where thousands of learners are grouped with almost no harm on the environment $[77,78]$.

- Help to enhance learners' skills and support lifelong learning [78,79].

- It considers as one of the best educational environment that support knowledge sharing professionally [78,79].

- Provide great chances to learners to meet admirable professors at well-known universities [80,81].

- Facilitate education by providing knowledge anytime, from anywhere with no coast [81,82].

- Different people from different cultures and regions are meet via MOOCs which make them great mean for cross-cultural relations [79].

However, there are a number of drawbacks that are realized as following:

- MOOCs with limited face to face learning procedure, could decrease the connectivity feeling which may affect learners' motivation [80,82].

- The rate of student dropout from MOOCs is significantly high $[14,83]$

- The pedagogical of MOOCs still needs to be standardized [84].

- Authentication matters when examining learner who may not the right one $[79,85]$.
- MOOCs are appropriate for self-directed learning, therefore, student who are not skilled with self-management would face difficulties in utilizing MOOCs [86].

\section{MATERIALS AND METHODS}

The most popular paradigms used for investigating human behaviour towards their use of technology are positivist paradigm, interpretivist paradigm and critical paradigm [87]. Moreover, there are three most popular research approaches that have been utilized by researchers in studying human behaviour toward the use of technologies, which arequantitative research approach, qualitative research approach and mixed method when researchers need to apply both quantitative C exploratory study that applies quantitative approach to collect descriptive information from the participants.

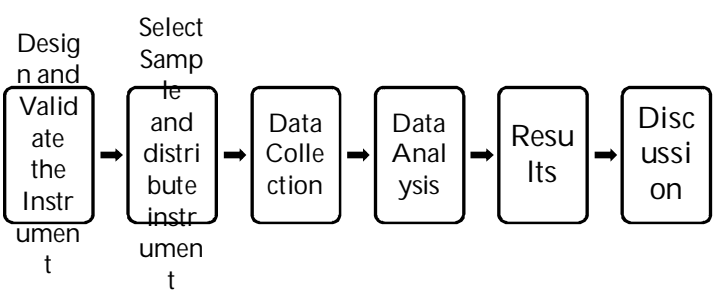

Figure 1.Description of the research method.

\subsection{Instruments}

The design of the questionnaire went through four stages. First, a review of literature was conducted to identify instruments applied in similar previous quantitative studies that are attempted to study the awareness and the utilization of ICT on learning procedure such as [88-93]. Second, after designing the questionnaire, content validation of the questionnaire was provided by three experts in Information Systems. Third, the distribution of the questionnaire attempted by the researchers after having a permeation from Umm Alqura University and Taif University. Fourth, the analysing of the data conducted to provide meaningful result.

The questionnaire contains eight questions. The first question aimed to inspect whether the students are in need to have additional programming learning courses or not. The second question was added to examine the awareness of CS students toward the available MOOCs provided for PLL. The third question was provided to see if students accept MOOCs as additional element on PLL procedure. The fourth question provided to know the willingness of students towards the use of MOOCs on PLL outside educational institutions. The fifth 
Ahmad Alaqsam et al., International Journal of Emerging Trends in Engineering Research, 9(2), February 2021, 116 - 131

question was given to illustrate the familiarity of students with the most known Arabic and English MOOCs platforms. The sixth and seventh questions show the frequent use of Arabic and English MOOCs on PLL. Finally, the eighth question was put to clarify the real beneficial utilization of MOOCs on PLL.

\subsection{Sampling method}

One of the most important steps in the research is selecting the participants or in other words sampling. This process has been defined as "the process of selecting a few from the many in order to carry out empirical research" [94] There are two main types of sampling, which are probability sampling and purposive sampling. Since this research mainly uses quantitative techniques, probability sampling is the best method. Pickard in [94]points out that quantitative research usually uses the probability sampling technique.

\subsection{Data collection}

The data collection attempted during July 2019. 170 questionnaires were disrupted. 90 questionnaires were allowed to be distributed at Umm Alqura University while 80 were allowed by Taif University. The number allowed based on the available students during the period of summer term. However, 68were received from Umm Alqura University and 64 from Taif University. The targeted students were from department of Computer Science, Information Technology, Information System, Information Science and Software Engineering that are belong to the faculty of Computing. It was insured that all participated students have been enrolled in programming language courses.

\subsection{Data Analysis}

The researchers provided questionnaire as hardcopies to faculty of computing in each university then collected them later. After that they analyse data, calculate results and draw graphs. As it is mentioned, the questionnaire includes eight questions, thus each question has its own result, graph and discussion.

\subsection{Procedures}

The study went through a number of processes as following:

1. The topic of the study was selected.
2. A number of materials were reviewed to identify the current situation.

3. The main objective of the research was defined and clarified.

4. The limitations were exhibited.

5. A review of the methodologies designed in previous research was conducted to allocate the convenient design of the research and the research approach.

6. To design the questionnaire, a literature review was done on the current studies that attempted to enhance the learners' utilization of MOOCs.

7. The data analysis was done.

8. Bar charts were provided to illustrate the result of the study.

9. Finally, a discussion of the finding was provided at the last section with the conclusion.

\section{RESULTS}

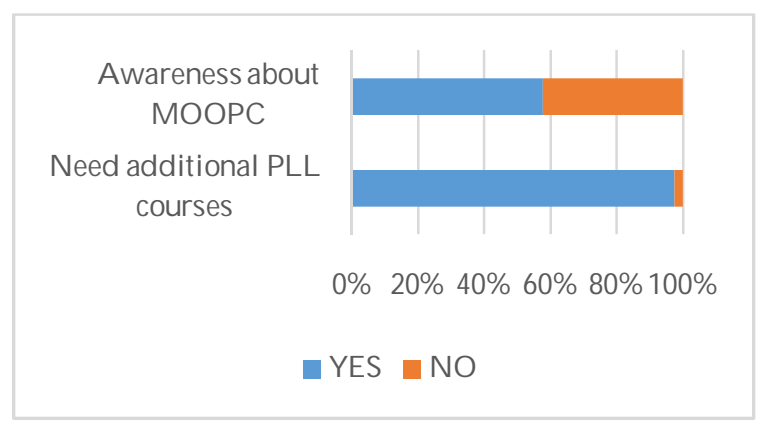

Figure 2.Percentage of the students' need for more PLL courses and their awareness about MOOCs on PLL.

As it can be seen from figure 2 above, the percentage of students who believe that there is a need for more PLL courses is $98 \%$. Almost all students believe that they need additional sessions and courses to enhance their PLL. It is clear indicator that the courses which are provided by universities are not sufficient and satisfied by learners. This result supports what it have been mentioned by researchers in Saudi that students need more support in PLL [5-8]

On the other hand, the graph clarifies the percentage of students who are aware of programming learning via MOOCs. About $60 \%$ of the learners are familiar with MOOCs provided for programming learning which elucidates the level of their awareness about MOOCs on PLL. However, $42 \%$ of unaware students is not a small number. This 
Ahmad Alaqsam et al., International Journal of Emerging Trends in Engineering Research, 9(2), February 2021, 116 - 131

indicates that a number of students need to be familiarized with MOOCs.

\begin{tabular}{|c|c|c|}
\hline \multicolumn{3}{|l|}{ Utilizing..- } \\
\hline $0 \%$ & $50 \%$ & $100 \%$ \\
\hline \multicolumn{3}{|c|}{ - Totally disagree } \\
\hline \multicolumn{3}{|c|}{ - Disagree } \\
\hline \multicolumn{3}{|c|}{ Agree } \\
\hline$\square \mathrm{Tc}$ & gree & \\
\hline
\end{tabular}

Figure 3.Percentage of the students' opinion on integrating and utilizing MOOCs on PLL.

It is clear from the above graph the percentage of the students' agreement for enhancing PLL via MOOCs, the majority of students with around $95 \%$ are agreed to adapt and integrate MOOCs in programming learning procedure. Also, it is shown that half of those who accept it are totally agreed. This is a good motivation for the researchers to continue his investigation.

Moreover, it is clear from the percentage of students who agree to use MOOCs on PLL that the willingness of students is acceptable. Interestingly, $56 \%$ agreed and $38 \%$ were more motivated and totally agreed. This is an evidence that students are interested to utilize effective MOOCs to enhance their level of programming learning even outside the university. However, the number of those who were not agreed is not significant at all.

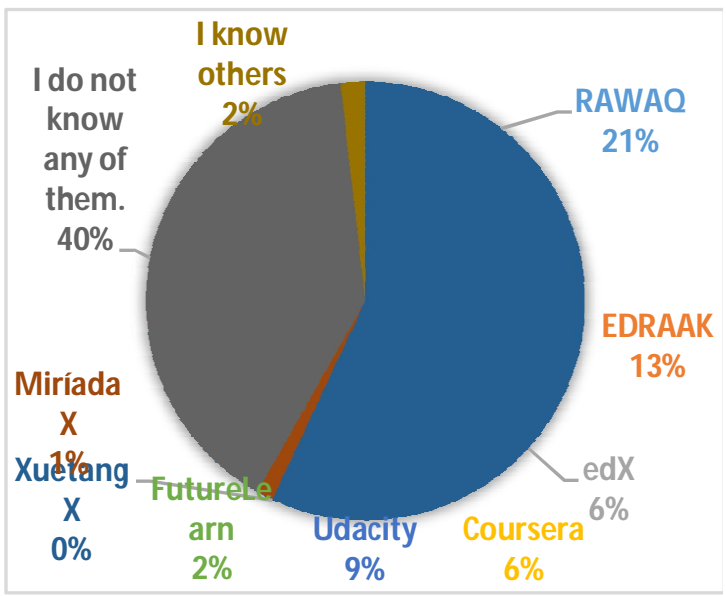

Figure 4.Percentage of student's familiarity with some popular MOOCs providers.

The above pie chart shows the percentage of students' familiarity with some popular MOOCs providers. it is a clear sign showed the weakness of students in utilizing MOOCs on PLL. It indicates

that $40 \%$ of the learners do not know about any of the available MOOC providers. The graph displays that $34 \%$ of the participants are familiar with Arabic MOOCs which are RAWAQ and EDRAAK [67] and just 24\% are aware of the English MOOCs platform which are edX, Coursera, Miriada, FutureLearn and Udacity [51] with 6\%, 6\%, 1\%, $2 \%$ and $9 \%$ respectively.

Usage frequency of..

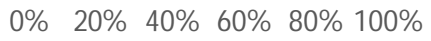

I do not use them
I use them 1-2 hours per week
I use them 2-4 hours per week
I use them 4-6 hours per week

Figure 5.Percentage of student's usage frequency of Arabic and English MOOCs on

PLL.

Figure 5presents the percentage of the students' usage frequency of Arabic and English MOOCs on PLL per week. As it is shown, about three quarters of the students do not utilize MOOCs on PLL at all. On the other hand, the number of students utilized MOOCs on PLL from 1-2 hours per week $19 \%$ which is not a satisfied number. In addition, handful of the learners used programming MOOCs more than 2 hours per week. This result clarify how far are Saudi students from utilizing MOOCs on PLL.

On the side of English MOOCs, it is shown that the number of users who perform 1-2 hours weekly reached $23 \%$ and those who utilize programming MOOCs more than 2 hours per week do not exceed $5 \%$. However, $72 \%$ of learners do not use programming MOOCs at all, this gives an indicator that there is a real need to initiate an investigation to identify the influences.

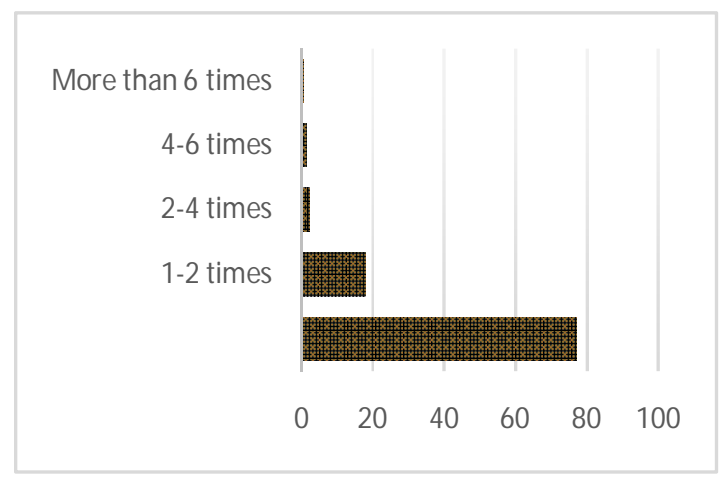

Figure 6. Percentage of students who already attended PLL courses via MOOCs. 
Ahmad Alaqsam et al., International Journal of Emerging Trends in Engineering Research, 9(2), February 2021, 116 - 131

As it can be seen, Figure 6 displays the percentage of the students who already attended PLL courses via MOOCs. Sadly, $77 \%$ of the participants have not enrolled and attended one programming language course. This is a strong indicator that CS students at Saudi university do not accept the current programming MOOCs. In addition, the graph shows that there are just about $18 \%$ of the learners attended 1-2 courses. And just 4\% of them completed more than 2 courses. This clarify that the students' acceptance is questionable.

\section{DISCUSSION AND CONCLUSION}

It is agreed that massive open online programming courses are effective mean in PLL and very good supporter for education of sustainable development. Therefore, MOOC technology is one of the best assistances that could be provided to CS students to enhance PLL at Saudi universities. However, this quantitative study shows notable results that will be discussed in the following section.

The survey shows as in figure 2 that $98 \%$ of the students need additional courses to enhance PLL which is supporting what has been mentioned by previous studies conducted in Saudi Arabia. Studies conducted at King Saud Universities, King Abdelaziz Universities, Tabuk University and also several investigations at different universities in Saudi Arabia state that students struggle with PLL and need more support [5-9].

However, although figure 2 points out that more effort required to develop MOOCs at Saudi universities and students should be educated and guided to be familiar with MOOCs [14,48].

Figure 3 also present significant result that clarifies the willingness of student to engage MOOCs in PLL procedure at universities. This is a good result which clears that students are eager to enhance the situation of PLL. This supports several previous investigations found that utilizing MOOCs in PLL is effective and preferable among a number of learners $[41,45]$.

On the other hand, as it is proven in figure 4 supports what it is given in figure 2 previously. Also, it indicates that students at Saudi Universities need to be introduced to the available MOOCs as already recommended in [14].

Figure 5 supports the previous investigations which highlighted that many students do not continue using MOOCs [14,95].

Figure 6 is a clear evidence that there is a need to understand the students' acceptance of utilizing MOOCs. This is not happened just in programming courses, the prior investigations show that the number of students who registered in MOOCs and did dropout have been quite high [14,48,83,96-98].
It is declared that in edX just 5\% of learners completed courses $[97,98]$. According to Feng et al.[83], after calculating the rate of students registered and attended in 1,000 courses on XuetangX, they found that just $4.5 \%$ of learners attended the courses [83].

As any information communication technology, the students' acceptance of MOOCs need to be investigated [14,99]. Consequently, researchers point out to the importance of investigating the factors that influence the behaviour of students towards the use of MOOCs. According to Hakami[48], there are a number of studies that investigate the students' acceptance of utilizing different kind of ICT in learning procedure, but still there is a need to investigate the students' acceptance of MOOCs. A number of researches highlight that investigating the behaviour of students towards the use of MOOCs will explains the students' motivation, engagement [72,73] and satisfaction[14,95]. It is emphasized that knowing the factors that influence the behaviour of learners towards their use of technology is an essential part of the development. Many studied mentioned that the motivation of students in utilizing ICTs affect their behaviour to accept them $[48,60]$, therefore MOOC designers should be aware of students' motivations to provide suitable learning platforms. It is emphasized that the behaviour of students and the contents of courses are main influences affecting learner's engagement in MOOCs [48,75]. Furthermore, Greene, Oswald, and Pomerantz[100] point out that MOOCs is not similar to other ICT educational tools. They emphasize that MOOCs have special features that need to be examine such as scalability, openness and diversity of participants. Moreover, providing MOOCs is not an easy affordable project. It is worthy to know that one massive open online course would cost 20000 -250000 USD [101,102]. According to Mutawa[15], designing a high quality massive open online courses platform that provides several kind of professional courses could costs millions of American dollars. This is one of the main reasons that encourage developers and decision makers to comprehend the learners acceptance of MOOCs [47,48].

Indeed, investigating the acceptance of PLL courses provided via MOOCs and other online learning resources is a requirement that have been asked by scholars. Korkmaz [103] stress that developing methods to solve matters affected learning of programming languages is depending on measuring factors that influence the behaviour of learners. they claim that there is a need to measure student behaviour and performance in programming language learning by finding a tested, reliable and valid scale that could be accepted in general. Li and 
Ahmad Alaqsam et al., International Journal of Emerging Trends in Engineering Research, 9(2), February 2021, 116 - 131

Tsai[104] point out that the performance and behaviour of students in learning programming languages via online learning tools is affected by their motivations, purposes of learning and preferences. Ozyurt[105] highlights that finding the relation between factors that affect the behaviour of ICT user in programming learning is a significant step. Also, they point out that researches in online programming languages learning are limited in terms of studying factors that affect students' behaviour. According to Ozyurt[105], yet, it is so difficult to find researches studied the behaviour of learners who study programming languages via Online tools. Clearly, Yagci[106] claims that understanding students' willingness by studying their inspiration, behaviour, thinking and the feature of programming courses is a significant step to design an appropriate programming learning tool.

As it has been stated, this piece of research aims to investigate whether the CS students at Saudi universities are willing to enhance PLL via MOOCs or not.After applying a quantitative research method, it is found that CS students are in need for more courses and sessions to enhance PLL. Also, it is proven that most CS students eager to implement MOOCs in PLL in educational procedure and during self-learning. Furthermore, the study declares that the utilization of MOOCs on PLL at Saudi Universities is seriously weak and need to be improved. PLL via MOOCS is recognized as one of the modern learning and teaching method that could be acceptable amongst CS . However, the students' behavior toward the utilization of MOOCs is not understood at Saudi Arabia universities.For future research, the researchers intend to investigate the influences that affect the students' utilization of MOOCs on PLL to propose an information system model that would demonstrates the needed requirements of successful massive open online programming courses. 
Ahmad Alaqsam et al., International Journal of Emerging Trends in Engineering Research, 9(2), February 2021, 116 - 131

Annex 1:

University name: $\quad$ Department:

This is a questionnaire provided by a $\mathrm{PhD}$ student from (UTM) UniversitiTeknologi Malaysia, undertaking a preliminary study to investigate the students' awareness and usage of (PMOOC) Programming Massive Open Online Courses in Saudi Arabia.

The MOOCs or Massive Open Online Courses are free courses that is provided in different fields. They are presented via online platforms that enable everyone anywhere to join and attend. They allow learners to communicate with each other and also with the instructor to enhance the chances of knowledge sharing. The results of the questionnaire will be treated confidently and used for research purposes.

Please answer the following questions:

Do you believe that there is a need for additional programming languages courses and sessions?

○ Yes

$\circ$ No

Do you know about massive open online programming courses?

○ Yes

$\circ$ No

Do you agree to enhance programming learning via massive open online programming courses?

○ Totally disagree

○ Disagree

- Agree

○ Totally agree

Do you agree to use massive open online programming courses?

○ Totally disagree

○ Disagree

- Agree

○ Totally agree

Which of the following massive open online courses platform do you know:
RAWAQ

\section{EDRAAK}

edX

\section{Coursera}

Udacity

FutureLearn

XuetangX

Miríada X

I do not know any of them.

I know others

What is your usage frequency of the Arabic massive open online programming courses Ex: RAWAQ?

○ I do not use them

○ I use them 1-2 hours per week

- I use them 2-4 hours per week

- I use them 4-6 hours per week

○ I use them more than 6 hours per week

What is your usage frequency of the English massive open online programming courses Ex: edX,

Coursera?

\begin{tabular}{ll}
\hline$\circ$ & I do not use them \\
$\circ$ & I use them 1-2 hours per week \\
$\circ$ & I use them 2-4 hours per week \\
$\circ$ & I use them 4-6 hours per week \\
$\circ$ & I use them more than 6 hours per week \\
\hline
\end{tabular}

How many times have you attended massive open online programming course completely?

○ I have not done any before.

○ 1-2 times

- 2-4 times

○ 4-6 times

- More than 6 times 
Ahmad Alaqsam et al., International Journal of Emerging Trends in Engineering Research, 9(2), February 2021, 116 - 131

\section{REFERENCES}

1. Lu, X.; Zheng, D.; Liu, L. Data driven analysis on the effect of online judge system. Proc. - 2017 IEEE Int. Conf. Internet Things, IEEE Green Comput. Commun. IEEE Cyber, Phys. Soc. Comput. IEEE Smart Data,

iThings-GreenCom-CPSCom-SmartData 20172018, 573-577.

2. Rohmeyer, R.; Espejo, P.S.; Sun, L. A Human Factors Perspective on Learning Programming Languages using a Second Language Acquisition Approach. In Proceedings of the American Society for Engineering Education; 2017; p. 8.

3. Luxton-Reilly, A. Learning to Program is Easy. Proc. 2016 ACM Conf. Innov. Technol. Comput. Sci. Educ. - ITiCSE '162016, 284-289.

4. Maravi, S.; Pinter, R. Code Hunt - “ Hunting" to Learn Programming. IEEE Int. Symp. Comput. Intell. Informatics $\mathbf{2 0 1 4}$ 329-333.

5. Garcia, R.A. Comprehensive Assessment on Factors Affecting Students' Performance in Basic Computer Programming Course towards the Improvement of Teaching Techniques. Int. J. Infonomics2013, 6, 682-691.

6. Alakeel, A.M. Investigating Difficulties of Learning Computer Programming in Saudi Arabia. Univers. J. Educ. Res.2015, 3, $567-577$.

7. Alshaye, I.A.; Jumaat, N.F.; Tasir, Z Programming Skills and the Relation in Fostering Students' Higher Order Thinking. Asian Soc. Sci.2018, 14, 76.

8. Ullah, Z.; Lajis, A.; Jamjoom, M.; Altalhi, A.; Al-Ghamdi, A.; Saleem, F. The effect of automatic assessment on novice programming: Strengths and limitations of existing systems. Comput. Appl. Eng. Educ.2018, 26, 2328-2341.

9. Moussa, W.E.; Almalki, R.M.; Alamoudi, M.A.; Allinjawi, A. Proposing a 3d interactive visualization tool for learning oop concepts. In Proceedings of the 2016 13th Learning and Technology Conference (L\&T); IEEE, 2016; pp. 1-7.

10. Stefik, A.; Siebert, S. An Empirical Investigation into Programming Language Syntax. ACM Trans. Comput. Educ.2013, $13,1-40$.

11. Sarkar, V.; Grossman, M.; Budimlic, Z.; Imam, S. A One Year Retrospective on a MOOC in Parallel, Concurrent, and Distributed Programming in Java. In Proceedings of the 2018 IEEE/ACM Workshop on Education for High-Performance Computing (EduHPC); IEEE, 2018; pp. 61-68.

12. Shin, J.; Jang, J.C.; Chae, H.; Ryu, G.; Yu, J.; Lee, J.R. A Web-Based MOOC Authoring and Learning System for Computational Science Education. In Proceedings of the 2018 IEEE International Conference on Teaching, Assessment, and Learning for Engineering (TALE); IEEE, 2018; pp. 1028-1032.

13. Malchow, M.; Bauer, M.; Meinel, C. Embedded smart home-remote lab MOOC with optional real hardware experience for over 4000 students. IEEE Glob. Eng. Educ. Conf. EDUCON2018, 2018-April, 1104-1111.

14. Alshehri, F.A. The Relationship between Learners' Motivation, Gender, and Completion of MOOCs in Saudi Arabia., ProQuest LLC. 789 East Eisenhower Parkway, P.O. Box 1346, Ann Arbor, MI 48106. Tel: 800-521-0600; Web site: http://www.proquest.com/en-US/products/di ssertations/individuals.shtml, 2018.

15. Mutawa, A.M. It is time to MOOC and SPOC in the Gulf Region. Educ. Inf. Technol.2017, 22, 1651-1671.

16. Ristić, O.; Milošević, D.; Urošević, V. The importance of programming language in education.; 6th International Conference, Faculty of Technical Sciences: Čačak, 
Ahmad Alaqsam et al., International Journal of Emerging Trends in Engineering Research, 9(2), February 2021, 116 - 131

Serbia, 2016; pp. 28-29.

17. Huang, T.-C.; Lee, S.; Shu, Y.; Huang, Y.-M.; Chang, S.-H.; Huang, Y.-Z.; Liu, C.-H. Developing a self-regulated oriented online programming teaching and learning system. J. Polym. Mater.2016, 33, 115-120.

18. Shaw, R.S. The relationships among group size, participation, and performance of programming language learning supported with online forums. Comput. Educ. 2013, 62, 196-207.

19. Saito, D.; Sasaki, A.; Washizaki, H. Quantitative Learning Effect Evaluation of Programming Learning Tools. 2017, 209-216.

20. Lee, M.J.; Ko, A.J. Comparing the Effectiveness of Online Learning Approaches on CS1 Learning Outcomes. Proc. Elev. Annu. Int. Conf. Int. Comput. Educ. Res. - ICER '152015, 237-246.

21. Wu, H.; Liu, Y.; Qiu, L.; Liu, Y. Online Judge System and Its Applications in C Language Teaching. In Proceedings of the IEEE Proceedings - 2016 International Symposium on Educational Technology, ISET; 2016; pp. 57-60.

22. Su, J.M.; Hsu, F.Y. Building a Visualized Learning Tool to Facilitate the Concept Learning of Object-Oriented Programming. Proc. - 2017 6th IIAI Int. Congr. Adv. Appl. Informatics, IIAI-AAI 20172017, 516-520.

23. Ali, A.; Smith, D. Teaching an Introductory Programming Language in a General Education Course. J. Inf. Technol. Educ. Innov. Pract.2014, 13, 57-67.

24. Longi, K. Exploring factors that affect performance on introductory programming courses, University of Helsinki, 2016.

25. Romero, C.; Espejo, P.G.; Zafra, A.; Romero, J.R.; Ventura, S. Web usage mining for predicting final marks of students that use Moodle courses. Comput. Appl. Eng. Educ.2013, 21, 135-146.

26. Cabada, R.Z.; Estrada, M.L.B.; Hernández, F.G.; Bustillos, R.O.; Reyes-García, C.A.
An affective and Web 3.0-based learning environment for a programming language. Telemat. Informatics2018, 35, 611-628.

27. Yan, Y.; Nakano, H.; Hara, K.; Kazuma, T.; He, A. A Web Service for C Programming Learning and Teaching. 2016 10th Int. Conf. Complex, Intelligent, Softw. Intensive Syst.2016, 414-419.

28. Offutt, J.; White, L.; Ammann, P.; Dobolyi, K.; Kauffmann, C.; Lester, J.; Praphamontripong, U.; Rangwala, H.; Setia, S.; Wang, P. A Novel Self-Paced Model for Teaching Programming. Proc. Fourth ACM Conf. Learn. @ Scale - L@S '172017, 177-180.

29. Cai, R. Adaptive Learning Practice for Online Learning and Assessment. Proc. 2018 Int. Conf. Distance Educ. Learn.2018, 103-108.

30. Keung, J.; Xiao, Y.; Mi, Q.; Lee, V.C.S. BlueJ-UML: Learning Object-Oriented Programming Paradigm Using Interactive Programming Environment. 2018 Int. Symp. Educ. Technol.2018, 47-51.

31. Song, S.H.; Antonelli, M.; Fung, T.W.K.; Armstrong, B.D.; Chong, A.; Lo, A.; Shi, B.E. Developing and Assessing MATLAB Exercises for Active Concept Learning. IEEE Trans. Educ. 2018, 1-9.

32. Rosato, J.; Lucarelli, C.; Beckworth, C.; Morelli, R. A Comparison of Online and Hybrid Professional Development for CS Principles Teachers. 2017, 140-145.

33. Mora, H.; Ferrández, A.; Gil, D.; Peral, J. A Computational Method for Enabling Teaching-Learning Process in Huge Online Courses and Communities. Int. Rev. Res. Open Distrib. Learn.2017, 18, 226-246.

34. Indi, T.S. An Experience Report of Flipped Classroom Strategy Implementation for Java Programming Course. Proc. - IEEE 8th Int. Conf. Technol. Educ. T4E 20162017, 240-241.

35. Hwang, G.J.; Liang, Z.Y.; Wang, H.Y. An Online Peer Assessment-Based 
Ahmad Alaqsam et al., International Journal of Emerging Trends in Engineering Research, 9(2), February 2021, 116 - 131

Programming Approach to Improving Students' Programming Knowledge and Skills. Proc. - 5th Int. Conf. Educ. Innov. through Technol. EITT 20162017, 81-85.

36. Teusner, R.; Hille, T.; Hagedorn, C. Aspects on finding the optimal practical programming exercise for MOOCs. Proc. Front. Educ. Conf. FIE2017, 2017-Octob, $1-8$.

37. Cabrera, I.; Villalon, J.; Chavez, J. Blending Communities and Team-Based Learning in a Programming Course. IEEE Trans. Educ.2017, 60, 288-295.

38. Malliarakis, C.; Satratzemi, M.; Xinogalos, S. CMX: The Effects of an Educational MMORPG on Learning and Teaching Computer Programming. IEEE Trans. Learn. Technol.2017, 10, 219-235.

39. Edwards, S.H.; Murali, K.P. CodeWorkout: Short Programming Exercises with Built-in Data Collection. ITiCSE '172017, 188-193.

40. Yulianto, B.; Prabowo, H.; Kosala, R.; Hapsara, M.; Link, S. MOOC Architecture Model for Computer Programming Courses Science Direct. 2016 Int. Conf. Inf. Manag. Technol.2016, 35-40.

41. Psathas, G. Profiles and motivations of participants in Greek. 2018 Learn. With MOOCS2018, 70-73.

42. Herrera-urgiles, J.; Peralta-bravo, A. Proposal for the inclusion of gamification elements in object-oriented programming through the use of MOOCs. In Proceedings of the Proceedings of the II International Conference MOOC-Maker; 2018; pp. 54-59.

43. Oktavia, T. The Comparison of MOOC Massive Open Online Course ) Platforms of edX and Coursera ( study case : student of programming courses ). 2018 Int. Conf. Inf. Manag. Technol.2018, 1-9.

44. Lepp, M.; Palts, T.; Luik, P.; Papli, K.; Suviste, R.; Säde, M.; Hollo, K.; Vaherpuu, V.; Tõnisson, E. Troubleshooters for tasks of introductory programming MOOCs. Int.
Rev. Res. Open Distance Learn. 2018, 19, 56-75.

45. Luik, P.; Suviste, R.; Lepp, M.; Palts, T.; Tõnisson, E.; Säde, M.; Papli, K. What motivates enrolment in programming MOOCs? Br. J. Educ. Technol.2019, 50, 153-165.

46. Mulik, S.; Yajnik, N.; Godse, M. Determinants of Acceptance of Massive Open Online Courses. In Proceedings of the Proceedings - IEEE 8th International Conference on Technology for Education, T4E 2016; 2017.

47. Ouyang, Y.; Tang, C.; Rong, W.; Zhang, L.; Yin, C.; Xiong, Z. Task-technology Fit Aware Expectation-confirmation Model towards Understanding of MOOCs Continued Usage Intention. In Proceedings of the Proceedings of the 50th Hawaii International Conference on System Sciences (2017); 2017; pp. 174-183.

48. Hakami, N.A.M. An Investigation of the Motivational Factors Influencing Learners' Intentions to Continue Using Arabic MOOCs, University of Southampton, University Library, 2018.

49. de Langen, F.; van den Bosch, H. Massive Open Online Courses: disruptive innovations or disturbing inventions? Open Learn. J. Open, Distance e-Learning2013, 28, 216-226.

50. Shah, D. By The Numbers: MOOCS in 2016 - Class Central Available online: https://www.classcentral.com/report/mooc-s tats-2016/ (accessed on Aug 26, 2019).

51. Shah, D. By The Numbers: MOOCs in 2018 - Class Central Available online: https://www.classcentral.com/report/mooc-s tats-2018/ (accessed on Aug 26, 2019).

52. Nordin, N.; Norman, H.; Embi, M.A. Technology Acceptance of Massive Open Online Courses in Malaysia. Malaysian J. Distance Educ.2016, 17, 1-16.

53. Zheng, S.; Rosson, M.B.; Shih, P.C.; Carroll, J.M. Understanding Student 
Ahmad Alaqsam et al., International Journal of Emerging Trends in Engineering Research, 9(2), February 2021, 116 - 131

Motivation, Behaviors and Perceptions in MOOCs. In Proceedings of the Proceedings of the 18th ACM Conference on Computer Supported Cooperative Work \& Social Computing - CSCW '15; ACM Press: New York, New York, USA, 2015; pp. 1882-1895.

54. Bayeck, R.Y. Exploratory study of MOOC learners' demographics and motivation: The case of students involved in groups. Open Prax.2016, 8 .

55. Garrido, M.; Koepke, L.; Anderson, S.; Felipe Mena, A.; Macapagal, M.; Dalvit, L. The Advancing MOOCs for Development Initiative: An examination of MOOC usage for professional workforce development outcomes in Colombia, the Philippines, \&amp; South Africa; Technology \& Social Change Group: Seattle, 2016;

56. Howarth, J.P.; D’Alessandro, S.; Johnson, L.; White, L. Learner motivation for MOOC registration and the role of MOOCs as a university 'taster.' Int. J. Lifelong Educ.2016, 35, 74-85.

57. Mihalec-Adkins, B.; Hicks, N.; Douglas, K.A.; Diefes-Dux, H.; Bermel, P.; Madhavan, K. Surveying the motivations of groups of learners in highly-technical STEM MOOCs. In Proceedings of the 2016 IEEE Frontiers in Education Conference (FIE); IEEE, 2016; pp. 1-6.

58. Salmon, G.; Pechenkina, E.; Chase, A.-M.; Ross, B. Designing Massive Open Online Courses to take account of participant motivations and expectations. Br. J. Educ. Technol.2017, 48, 1284-1294.

59. Uchidiuno, J.; Ogan, A.; Yarzebinski, E.; Hammer, J. Understanding ESL Students' Motivations to Increase MOOC Accessibility. In Proceedings of the Proceedings of the Third (2016) ACM Conference on Learning @ Scale - L@S '16; ACM Press: New York, New York, USA, 2016; pp. 169-172.

60. Alario-Hoyos, C.; Estévez-Ayres, I.;
Pérez-Sanagustín, M.; Delgado Kloos, C.; Fernández-Panadero, C. Understanding Learners' Motivation and Learning Strategies in MOOCs. Int. Rev. Res. Open Distrib. Learn.2017, 18.

61. Annaraud, K.; Singh, D. Perceptions of Hospitality Faculty and Students of Massive Open Online Courses (MOOCs). J. Hosp. Tour. Educ.2017, 29, 82-90.

62. Loizzo, J.; Ertmer, P.; Watson, W.; Watson, S. Adult MOOC Learners as Self-Directed: Perceptions of Motivation, Success, and Completion. ERIC2017, 21.

63. Milligan, C.; Littlejohn, A. Why study on a MOOC: the motives of students and professionals. Int. Rev. Res. Open Distrib. Learn.2017, 18, 102.

64. Nagasampige, M.H.; Nagasampige, K. A Qualitstive Study on Usage and Effectiveness of Massive Open Online Courses (MOOCs) in Indian University Education System. Eur. J. Open Educ. E-learning Stud.2017, 2, 79

65. Shapiro, H.B.; Lee, C.H.; Wyman Roth, N.E.; Li, K.; Çetinkaya-Rundel, M.; Canelas, D.A. Understanding the massive open online course (MOOC) student experience: An examination of attitudes, motivations, and barriers. Comput. Educ.2017, 110, 35-50.

66. Souhem Badi, D.; Manal Elsayed Ahmed Ali, D. Massive Open Online Courses (MOOC) Their Impact on the Full Quality in Higher Education Institutions "Rwaq: Saudi educational platform for MOOC". $J$. Libr. Inf. Sci.2016, 4.

67. Sallam, M.H. A Review of MOOCs in the Arab World. Creat. Educ.2017, 08, $564-573$

68. Jemni, M.; Khribi, M.K. Toward Empowering Open and Online Education in the Arab World Through OER and MOOCs. In Open Education: from OERs to MOOCs; Springer, Berlin, Heidelberg, 2017; pp. 73-100 
Ahmad Alaqsam et al., International Journal of Emerging Trends in Engineering Research, 9(2), February 2021, 116 - 131

69. Almuhanna, M. Participants' Perceptions of MOOCs in Saudi Arabia, University of Sheffield, 2018.

70. Almutairi, F. The Impact of Integrating MOOCs into Campus Courses on Student Engagement, SOUTHAMPTON, 2018.

71. Carrera, J.; Ramírez-Hernández, D. Innovative Education in MOOC for Sustainability: Learnings and Motivations. Sustainability2018, 10, 2990.

72. Kizilcec, R.; Schneider, E. Motivation as a Lens to Understand Online Learners: Toward Data-Driven Design with the OLEI Scale. ACM Trans. Comput. Interact.2015, $22,1-24$

73. de Barba, P.G.; Kennedy, G.E.; Ainley, M.D. The role of students' motivation and participation in predicting performance in a MOOC. J. Comput. Assist. Learn.2016, 32, 218-231.

74. Gameel, B.G. Learner Satisfaction with Massive Open Online Courses. Am. J. Distance Educ.2017, 31, 98-111.

75. Pilli, O.; Admiraal, W. Students' learning outcomes in Massive Open Online Courses (MOOCs): Some suggestions for course design. J. Higher Educ.2017, 7, 46-62.

76. Economides, A.; Perifanou, M. MOOC affordances model; 2018;

77. Ortega-Sánchez, D.; Gómez-Trigueros, I. Massive Open Online Courses in the Initial Training of Social Science Teachers: Experiences, Methodological Conceptions, and Technological Use for Sustainable Development. Sustainability2019, 11, 578.

78. Rao, P.N.; Komaraiah, M.; Narasimha Reddy, P. A Case for MOOCs in Indian Higher Education System. J. Eng. Educ. Transform.2015, 29, 15.

79. Sonwalkar, J.; Maheshkar, C. MOOCs: A Massive Platform for Collaborative Learning in Globalizzaed Way. J. Manag. Res. Anal.2015, 2, 142-149.

80. Lopes, A.; Soares, F.; Vieira, I. A New Horizon for Online Teaching and Learning.
In Proceedings of the EDULEARN14 Proceedings; International Association of Technology, Education and Development (IATED), 2014; pp. 5328-5335.

81. YU, C.; YU, C. Challenges and Changes of MOOC to Traditional Classroom Teaching Mode. Can. Soc. Sci.2015, 11, 135-139.

82. Baker, C.; Nafukho, F.; McCaleb, K.; Becker, M.; Johnson, M. The Tangible and Intangible Benefits of Offering Massive Open Online Courses: Faculty Perspectives. Internet Learn.2015, 4.

83. Feng, W.; Tang, J.; Liu, T.X. Understanding Dropouts in MOOCs. Assoc. Adv. Artif. Intell.2019, 1,8 .

84. Atiaja, L.; Guerrero-Proenza, R.S. The MOOCs: origin, characterization, principal problems and challenges in Higher Education. J. E-Learning Knowl. Soc.2016, $12,65-76$.

85. YU, C. Challenges and Changes of MOOC to Traditional Classroom Teaching Mode. Can. Soc. Sci.2015, 11, 135-139.

86. Ejreaw, A.M.; Drus, S.M. The challenges of massive open online courses (MOOC)- A preliminary review. In Proceedings of the Proceedings of the 6th International Conference on Computing \& Informatics; Malaysia, 2017; pp. 473-479.

87. Candy. P.C. Constructivism and the study of'self-direction in adult learning. Stud. Educ. Adults1989, 21, 95-116.

88. Muzafarova, T.; Kaya, E. Survey of Awareness of Massive Open Online Courses (MOOC) - a Case of International Black Sea University Students, Georgia. In Proceedings of the Journal of Education; 2014; Vol. 3, pp. 15-19.

89. Shakya, M.; Shrestha, S.; Manandhar, R. Awareness of MOOC Among College Students: A Study Of Far Western Region of Nepal. In Proceedings of the Conference: Internation Conference on IT4D; 2016; p. 9.

90. Dhanani, J.; Chavda, N.; Patel, N.; Tandel, $\mathrm{K}$. Awareness and utilization of massive 
Ahmad Alaqsam et al., International Journal of Emerging Trends in Engineering Research, 9(2), February 2021, 116 - 131

open online course (MOOC) and video series as continuous learning tools for faculties. Int. J. Med. Sci. Public Heal.2016, 5,1540 .

91. Hone, K.S.; El Said, G.R. Exploring the factors affecting MOOC retention: A survey study. Comput. Educ.2016, 98, 157-168.

92. $\mathrm{Wu}, \mathrm{B}$; Chen, $\mathrm{X}$. Continuance intention to use MOOCs: Integrating the technology acceptance model (TAM) and task technology fit (TTF) model. Comput. Human Behav.2017, 67, 221-232.

93. Khan, I.U.; Hameed, Z.; Yu, Y.; Islam, T.; Sheikh, Z.; Khan, S.U. Predicting the acceptance of MOOCs in a developing country: Application of task-technology fit model, social motivation, and self-determination theory. Telemat. Informatics 2018, 35, 964-978.

94. Pickard, A.J. Research methods in information; Facet, 2007; ISBN 9781856045452.

95. Othman, E.H.; Abdelali, S.; Jaber, E.B Education data mining: Mining MOOCs videos using metadata based approach. Colloq. Inf. Sci. Technol. Cist2017, 531-534.

96. He, J.; Rubinstein, B.I.P.; Zhang, R. Identifying at-risk students in massive open online courses. Proc. Twenty-Ninth AAAI Conf. Artif. Intell.2015, 1749-1755.

97. Kizilcec, R.F.; Piech, C.; Schneider, E. Deconstructing disengagement. In Proceedings of the Proceedings of the Third International Conference on Learning Analytics and Knowledge - LAK '13; ACM Press: New York, New York, USA, 2013; p. 170.

98. Seaton, D.; Bergner, Y.; Chuang, I.; Mitros, P.; Pritchard, D.E. Who does what in a massive open online course? Commun. ACM2014, 57, 58-65.
99. Tarhini, A.; Hone, K.; Liu, X. The effects of individual differences on e-learning users' behaviour in developing countries: A structural equation model. Comput. Human Behav.2014, 41, 153-163.

100. Greene, J.A.; Oswald, C.A.; Pomerantz, J. Predictors of Retention and Achievement in a Massive Open Online Course. Am. Educ. Res. J.2015, 52, 925-955.

101. Peterson, R. What Do MOOCs Cost? Minding The Campus Available online: https://www.mindingthecampus.org/2013/0 9/17/what_do_moocs_cost/ (accessed on Aug 29, 2019).

102. Hollands, F.; Tirthali, D. View of Resource requirements and costs of developing and delivering MOOCs | The International Review of Research in Open and Distributed Learning Available online: http://www.irrodl.org/index.php/irrodl/articl e/view/1901/3069 (accessed on Aug 29, 2019).

103. KORKMAZ, Ö.; Altun, H. Adapting Computer Programming Self-Efficacy Scale and Engineering Students' Self-Efficacy Perceptions. Particip. Educ. Res.2014, 1, 20-31.

104. Li, L.Y.; Tsai, C.C. Accessing online learning material: Quantitative behavior patterns and their effects on motivation and learning performance. Comput. Educ.2017, 114, 286-297.

105. Ozyurt, O. An analysis on distance education computer programming students' attitudes regarding programming and their self-efficacy for programming. Turkish Online J. Distance Educ.2015, 16, 111-121.

106. Yağci, M. Blended learning experience in a programming language course and the effect of the thinking styles of the students on success and motivation. Turkish Online J. Educ. Technol.2016, 15, 32-45. 